
\title{
28 Research Suare \\ Variation of heart and lung radiation doses according to setup uncertainty in left breast cancer
}

\section{Sunmin Park}

Korea University Ansan Hospital

\section{Chai Hong Rim}

Korea University Ansan Hospital

Won Sup Yoon ( $\nabla$ irionyws@korea.ac.kr)

Korea University Ansan Hospital https://orcid.org/0000-0002-6098-1993

\section{Research}

Keywords: Breast cancer, Radiotherapy, Set-up Uncertainty, Deep Inspiration Breath Holding, Heart

Posted Date: January 27th, 2021

DOI: https://doi.org/10.21203/rs.3.rs-104606/v2

License: (1) This work is licensed under a Creative Commons Attribution 4.0 International License.

Read Full License

Version of Record: A version of this preprint was published at Radiation Oncology on April 20th, 2021. See the published version at https://doi.org/10.1186/s13014-021-01806-5. 


\section{Abstract}

Purpose: Breast radiotherapy set-up is often uncertain. Actual dose distribution to normal tissues could be different from planned dose distribution. The objective of this study was to investigate such difference in dose distribution according to the extent of set-up error in breast radiotherapy.

Materials and methods: A total of 50 Gy with fraction size of 2 Gy was given to 30 left breasts with different set-ups applying a deep inspiration breath holding (DIBH) or a free breathing (FB) technique. Under the assumption that errors might come from translational axes of deep or caudal directions, the isocenter was shifted from the original tangential alignment every $2.5 \mathrm{~mm}$ to simulate uncertainty of deep and caudal tangential set-up in DIBH and FB. Changes were evaluated for dosimetric parameters for the heart, the left ventricle (LV), the left anterior descending coronary artery (LAD), and the ipsilateral lung.

Results: On the original plan, mean doses of heart and ipsilateral lung were $2.0 \pm 1.1 \mathrm{~Gy}$ and $3.7 \pm 1.4 \mathrm{~Gy}$ in DIBH and $8.4 \pm 1.3 \mathrm{~Gy}$ and $7.8 \pm 1.5 \mathrm{~Gy}$ in $\mathrm{FB}$, respectively. The change of dose distribution for the heart in DIBH was milder than that in FB. The deeper the tangential set-up, the worse the heart, LV, LAD, and ipsilateral lung doses, showing as much as $49.4 \%, 56.4 \%, 90.3 \%$, and $26.1 \%$ shifts, respectively, in $5 \mathrm{~mm}$ DIBH setup. The caudal set-up did not show significant dose difference. In multiple comparison of DIBH, differences of mean dose occurred in all $7.5 \mathrm{~mm}$ deep set-ups for the heart $(p=0.025)$, the LV $(p=0.049)$, and LAD $(p=0.025)$ in DIBH.

Conclusions: To correct set-up error over indicated limitation for deep tangential set-up in DIBH at $5 \mathrm{~mm}$ action level, mean heart and ipsilateral lung doses are expected to increase approximately $50 \%$ and $25 \%$, respectively.

\section{Introduction}

The issue of cardiac toxicity after breast radiotherapy was raised in the early 2000 's. It has the following features. First, atherosclerotic change can cause coronary damage.(1) Second, cardiac events have continuously increased over a decade after radiotherapy. Therefore, long-term observation is needed. $(2,3)$ Third, pre-existing risk factors such as smoking, old age, obesity, cardio-metabolic risk factors of hypertension and diabetes, and other cardiovascular or cerebrovascular disease can affect cardiac toxicity.(4-6) Most importantly, cardiac toxicity increases gradually per mean heart dose without a clear threshold.(7) Therefore, radiation dose for the heart should be avoided as low as reasonably achievable. The expert consensus has recommended deep inspiration breath hold (DIBH), prone position, and/or heart blocks to minimize heart dose.(8) The technique of DIBH is currently being applied to left breast cancer in many institutions. One study has compared DIBH and free breathing (FB) and found that DIBH can decrease $29.2 \%$ of mean heart dose and $43.5 \%$ of mean left anterior descending coronary artery (LAD) dose.(9) In a Asian cohort, the mean heart dose reduction throughout DIBH compared to FB is $47 \%$. This effect is more significant in those with low body mass index.(10) 
Tangential irradiation method is considered the most common and effective method in whole breast radiotherapy to minimize radiation dose to the opposite breast. In recent years, field-in-field techniques have been combined to further reduce ambient dose. However, because of uneven body surface, irregular breathing, incomplete body fixation, soft breast tissue, and so on, set-up uncertainty has become a limiting factor for distributing radiation dose as planned.(11) Then, with a deep set-up which is harmful to normal tissues such as the heart or the ipsilateral lung, to what extent is the radiation dose exceeded and what is the acceptable action level to correct set-up errors in clinical practice? No studies have addressed these questions. Thus, the objective of this study was to investigate dose distribution in the organs at risk (OARs) of heart, sub-segments of heart, and ipsilateral lungs according to set-up uncertainty, analyze characteristics, and assume the dose increase of OARs according to the action level of set-up error.

\section{Methods And Materals}

\section{Patients}

Each of 15 patients with left breast cancer who underwent adjuvant radiotherapy for whole breast alone were identified in DIBH and FB through data review. All patients received breast conserving surgery including sentinel lymph node biopsy with clinical T1-2NO stage. Because our institution has applied DIBH since October 2019, 15 patients consecutive from November 2019 to February 2020 were selected for the DIBH group. To minimize the effect of OARs by the different characteristics of body contour between DIBH and FB groups, FB group was selected based on clinical target volume (CTV) of breast.(12) Of 33 patients from October 2017 to May 2018, 15 patients for the FB group were paired with the DIBH group considering the approximate CTV. This retrospective study was approved by the Institutional Review Board of Ansan Hospital, Korea University, Republic of Korea.

For computed tomography (CT) simulation, a Brilliance Big Bore Oncology CT system (Philips Medical Systems, Nederland) and a Breastboard (Civco, Orange City, IA, USA) as immobilization devices were utilized. All set-ups were done at a supine position with an elevation of both arms above the head. CT contrast was administrated to enhance vascular structures and tumor bed. CT scans were sliced with a thickness of $3 \mathrm{~mm}$. While there was no education of breathing control for the FB group, the concept of DIBH was explained to patients on the first consultation day. Self-training was proceeded to hold their breath for a minimum of $20 \mathrm{sec}$ with a feeling of inhaling a small $1000 \mathrm{cc}$ plastic bottle for the DIBH group. Patients who had difficulty holding their breath for more than 20 seconds in the prior practice were excluded in DIBH. Our institution performed daily verification using the electronic portal images, Portal Vision aS1000 (Varian Medical System, Palo Alto, CA, USA) and checked the stability of chest wall during DIBH using the Real Time Position Management system (Varian Medical System).

\section{Radiotherapy planning}

Dose distribution was calculated with a radiation therapy planning system, a Varian Eclipse version 15.1 (Varian Medical System) using Anisotropic Analytical Algorithm. For CTV of the whole breast, ESTRO guideline was considered and $5 \mathrm{~mm}$ from the body surface of the CTV (4 mm for the small sized breast 
less than $400 \mathrm{cc}$ ) was edited.(13) To delineate OARs of the heart and sub-segments (left ventricle (LV) and LAD) of heart, the report of cardiac contouring atlas by Duane et al.(14) was used as a reference. The ipsilateral lung was delineated with CT window level and width of 0/1000 HU. The prescribed dose was modified as 50 Gy with 25 fractions to all patients to cover CTV > 95\% with prescribed dose $>95 \%$ without maximum CTV dose $>107 \%$. The field-in-field technique using $6 \mathrm{MV}$ photon beams was made. For this study, delineation of the CTV and OARs and treatment plans were newly verified in consultation with two experienced radiation oncologists (Yoon and Rim).

\section{Study simulation}

For this study, we simulated two main conditions of set-up error in a separate way: 1) in the deep direction (virtual perpendicular direction from the original tangential alignments); and 2) in the caudal direction of iso-center. Under the assumption that errors from rotational position and other directions were corrected, the isocenter shifted in deep and caudal directions every $2.5 \mathrm{~mm}$ until reaching $15 \mathrm{~mm}$ error.

(Figure 1) After the isocenter was moved as much as each set-up error, dose distribution was recalculated. Thus, uncertainties of deep tangential and caudal set-up were simulated.

\section{Statistics}

Mean dose, V10Gy, and V20Gy of heart, mean dose and V20Gy of LV, mean dose and V30Gy of LAD, and mean dose, V10Gy, and V30Gy of ipsilateral lung were measured. Each parameter was presented with a mean (M) \pm standard deviation (SD). The difference between FB and DIBH groups was examined with an independent two sample T-test. The difference in dose distribution between the original plan and each simulated set-up plan was calculated in both absolute dose (Gy) and the relative ratio on the basis of the original dose (\%). Then, it was compared with a paired T-test. In addition, multiple comparisons were performed with LSD (least significant difference) method to compare differences between simulated setups and to search the point as action level. A two-sided $p<0.05$ was considered significant. SPSS 20.0 (IBM SPSS Inc., Chicago, IL, USA) was used for all statistical analyses.

\section{Results}

\section{Patient characteristics}

After matching DIBH and FB groups according to CTV, 15 patients in each group were selected. Median age was 54 years (range, 41-66 years) for the DIBH group and 48 years (range, 39-63 years) for the FB group. For OARs, the ipsilateral lung (mean $923.1 \mathrm{ml}$ vs. $1600.7 \mathrm{ml}, \mathrm{p}<0.001$ ) was larger in DIBH group. However, there was no volume difference of heart or its sub-segments.(Table 1) 
Table 1. Patient characteristics

\begin{tabular}{|c|c|c|c|c|c|}
\hline & \multicolumn{2}{|c|}{$\begin{array}{l}\text { Deep inspiration breath hold } \\
\qquad(\mathrm{N}=15)\end{array}$} & \multicolumn{2}{|c|}{ Free breath $(\mathrm{N}=15)$} & \\
\hline pT-stage 0: 1: 2 & \multicolumn{2}{|c|}{$1 *: 9: 5$} & \multicolumn{2}{|c|}{$0: 9: 6$} & \\
\hline \multirow[t]{2}{*}{ pN-stage $0: 1$} & \multicolumn{2}{|c|}{ 14: 1} & \multicolumn{2}{|c|}{$14: 1$} & \\
\hline & Median & Range & Median & Range & $P$ value*** \\
\hline Age (years) & 54 & $41-66$ & 48 & $39-63$ & 0.715 \\
\hline Tangential angle $\left({ }^{\circ}\right)$ & 311 & $306-318$ & 312 & $302-316$ & 1.000 \\
\hline \multirow[t]{2}{*}{ Field height $(\mathrm{cm})$} & 20 & $17-22$ & 20 & $18-21.5$ & 0.245 \\
\hline & Mean & SD & Median & SD & P value*** \\
\hline $\begin{array}{ll}\text { Clinical target } & \text { talume }(\mathrm{ml}) \\
\text { volum }\end{array}$ & 682.2 & 280.6 & 669.2 & 242.9 & 0.892 \\
\hline Heart (ml) & 616.0 & 82.2 & 645.1 & 81.5 & 0.339 \\
\hline Left ventricle $(\mathrm{ml})$ & 151.1 & 22.6 & 160.7 & 26.8 & 0.298 \\
\hline $\begin{array}{l}\text { Left anterior } \\
\text { descending } \\
\text { coronary artery }(\mathrm{ml})\end{array}$ & 1.1 & 0.1 & 1.1 & 0.1 & 0.271 \\
\hline Lung, Ipsilateral (ml) & 1600.7 & 409.4 & 923.1 & 227.6 & $<0.001$ \\
\hline
\end{tabular}

* Patient had complete response after receiving neoadjuvant chemotherapy

** The median value was compared through a Mann-Whitney U-test.

*** The mean value was compared through an independent two sample T-test.

\section{Original plan of DIBH and FB}

On the original plan, mean doses of the heart were $2.0 \pm 1.1 \mathrm{~Gy}$ (range, $0.85-4.95 \mathrm{~Gy}$ ) and $3.7 \pm 1.4 \mathrm{~Gy}$ (range, $1.7-6.15 \mathrm{~Gy}$ ) in DIBH and FB groups, respectively. Mean doses of LV and LAD were $3.3 \pm 2.5 \mathrm{~Gy}$ and 17.8 $\pm 12.7 \mathrm{~Gy}$ in DIBH and $6.0 \pm 2.3 \mathrm{~Gy}$ and $35.9 \pm 9.6 \mathrm{~Gy}$ in FB, respectively. These results showed benefits of DIBH for decreasing doses for heart and its sub-segments in comparison with FB. Mean doses of the ipsilateral lung were $8.4 \pm 1.3 \mathrm{~Gy}$ (range, $6.1-11.1 \mathrm{~Gy}$ ) and $7.8 \pm 1.5 \mathrm{~Gy}$ (range, $5.7-11.4 \mathrm{~Gy}$ ) in DIBH and FB groups, respectively.

\section{Extent of dose difference}

The deeper the tangential set-up, the worse the OARs dose. However, caudal set-up did not affect dose distribution of OARs in DIBH or FB group.(Table 2) 
Table 2. Dose distribution for the organ at risks in terms of deep and caudal set-up errors in deep inspiration breath hold and free breath.

\begin{tabular}{|c|c|c|c|c|c|c|c|c|c|c|c|}
\hline & & \multicolumn{3}{|c|}{ Heart } & \multicolumn{2}{|c|}{ Left ventricle } & \multicolumn{2}{|c|}{$\begin{array}{c}\text { Left anterior } \\
\text { descending coronary } \\
\text { artery }\end{array}$} & \multicolumn{3}{|c|}{ Lung, Ipsilateral } \\
\hline & & $\begin{array}{c}\text { Mean } \\
\text { (Gy) }\end{array}$ & $\begin{array}{c}\text { V10Gy } \\
(\%)\end{array}$ & $\begin{array}{l}\text { V20Gy } \\
(\%)\end{array}$ & $\begin{array}{l}\text { Mean } \\
\text { (Gy) }\end{array}$ & $\begin{array}{l}\text { V20Gy } \\
(\%)\end{array}$ & $\begin{array}{c}\text { Mean } \\
\text { (Gy) }\end{array}$ & $\begin{array}{c}\text { V30Gy } \\
(\%)\end{array}$ & $\begin{array}{c}\text { Mean } \\
\text { (Gy) }\end{array}$ & $\begin{array}{l}\text { V10Gy } \\
(\%)\end{array}$ & $\begin{array}{c}\text { V30Gy } \\
(\%)\end{array}$ \\
\hline \multicolumn{12}{|c|}{$\begin{array}{l}\text { Deep inspiration } \\
\text { breath hold }(\mathrm{N}=15)\end{array}$} \\
\hline No Shift & & $2.0(1.1)$ & $2.8(2.7)$ & $2.1(2.3)$ & $3.3(2.5)$ & $3.8(5.1)$ & $\begin{array}{c}17.8 \\
(12.7)\end{array}$ & $\begin{array}{c}29.3 \\
(31.2)\end{array}$ & $8.4(1.3)$ & $19.7(3.1)$ & $12.8(2.7)$ \\
\hline \multirow[t]{6}{*}{ Deep } & $2.5 \mathrm{~mm}$ & $2.5(1.4)$ & $3.8(3.2)$ & $2.9(2.8)$ & $4.1(2.9)$ & $5.4(6.3)$ & $\begin{array}{c}22.2 \\
(13.2)\end{array}$ & $\begin{array}{c}38.7 \\
(31.8)\end{array}$ & $9.4(1.3)$ & $22.1(3.2)$ & $15.0(2.9)$ \\
\hline & $5 \mathrm{~mm}$ & $3.0(1.6)$ & $4.9(3.8)$ & $3.9(3.3)$ & $5.0(3.4)$ & $7.4(7.3)$ & $\begin{array}{c}26.9 \\
(13.0)\end{array}$ & $\begin{array}{c}50.9 \\
(30.6) \\
\end{array}$ & $10.5(1.3)$ & $24.6(3.2)$ & $17.2(2.9)$ \\
\hline & $7.5 \mathrm{~mm}$ & $3.6(1.8)$ & $6.3(4.3)$ & $5.1(3.8)$ & $6.2(3.9)$ & $9.9(8.4)$ & $\begin{array}{c}31.4 \\
(12.9)\end{array}$ & $\begin{array}{c}61.7 \\
(29.3) \\
\end{array}$ & $11.6(1.4)$ & $27.1(3.3)$ & $19.6(2.9)$ \\
\hline & $10 \mathrm{~mm}$ & $4.3(2.1)$ & $7.9(4.8)$ & $6.6(4.4)$ & $7.5(4.3)$ & $12.7(9.5)$ & $\begin{array}{c}35.1 \\
(13.1)\end{array}$ & $\begin{array}{c}69.9 \\
(30.5) \\
\end{array}$ & $12.8(1.4)$ & $29.6(3.4)$ & $22.0(3.0)$ \\
\hline & $12.5 \mathrm{~mm}$ & $5.0(2.3)$ & $9.7(5.3)$ & $8.2(4.90$ & $8.9(4.7)$ & $\begin{array}{c}15.8 \\
(10.5)\end{array}$ & $\begin{array}{c}38.0 \\
(13.1)\end{array}$ & $\begin{array}{c}76.0 \\
(32.0)\end{array}$ & $13.9(1.4)$ & $32.0(3.4)$ & $24.4(3.0)$ \\
\hline & $15 \mathrm{~mm}$ & $5.9(2.5)$ & $11.7(5.8)$ & $10.0(5.4)$ & $10.5(5.1)$ & $19.3(4.3)$ & $\begin{array}{c}40.7 \\
(12.1) \\
\end{array}$ & $\begin{array}{c}81.0 \\
(30.4) \\
\end{array}$ & $15.0(1.5)$ & 34.5 (3.5) & $26.9(3.1)$ \\
\hline \multirow[t]{3}{*}{ Caudal } & $5 \mathrm{~mm}$ & $2.1(1.2)$ & $3.0(2.8)$ & $2.3(2.4)$ & $3.5(2.6)$ & $4.1(5.4)$ & $\begin{array}{c}18.7 \\
(13.0)\end{array}$ & $\begin{array}{c}32.3 \\
(30.8) \\
\end{array}$ & $8.6(1.2)$ & $20.3(2.9)$ & $13.4(2.6)$ \\
\hline & $10 \mathrm{~mm}$ & $2.2(1.2)$ & $3.2(3.0)$ & $2.5(2.5)$ & $3.7(2.7)$ & $4.5(5.7)$ & $\begin{array}{c}19.6 \\
(13.2)\end{array}$ & $\begin{array}{c}32.9 \\
(32.6)\end{array}$ & $8.9(1.1)$ & $20.9(2.7)$ & $14.0(2.3)$ \\
\hline & $15 \mathrm{~mm}$ & $2.3(1.3)$ & $3.5(3.2)$ & $2.7(2.7)$ & $3.9(2.9)$ & 4.9() $6.1)$ & $\begin{array}{c}20.6 \\
(13.5) \\
\end{array}$ & $\begin{array}{c}34.7 \\
(32.1) \\
\end{array}$ & $9.1(1.0)$ & $21.4(2.6)$ & $14.5(2.1)$ \\
\hline \multicolumn{12}{|c|}{ Free breath $(\mathrm{N}=15)$} \\
\hline No Shift & & $3.7(1.4)$ & $6.6(3.2)$ & $5.3(2.8)$ & $6.0(2.3)$ & $9.1(5.2)$ & $35.9(9.6)$ & $\begin{array}{c}72.6 \\
(24.7)\end{array}$ & $7.8(1.5)$ & $17.7(3.6)$ & $11.9(3.2)$ \\
\hline \multirow[t]{6}{*}{ Deep } & $2.5 \mathrm{~mm}$ & $4.5(1.5)$ & $8.4(3.5)$ & $7.0(3.2)$ & $7.4(2.5)$ & $12.2(5.7)$ & $40.2(6.8)$ & $\begin{array}{c}83.8 \\
(15.5) \\
\end{array}$ & $8.9(1.5)$ & $20.2(3.7)$ & $14.2(3.3)$ \\
\hline & $5 \mathrm{~mm}$ & $5.4(1.7)$ & $10.4(3.9)$ & $8.8(3.5)$ & $9.0(2.7)$ & $15.7(6.1)$ & $42.9(5.4)$ & $\begin{array}{c}89.0 \\
(12.2) \\
\end{array}$ & $10.1(1.6)$ & $22.7(3.8)$ & $16.7(3.4)$ \\
\hline & $7.5 \mathrm{~mm}$ & $6.4(1.8)$ & $12.7(4.2)$ & 10.9 (3.9) & $10.7(2.8)$ & $19.5(6.5)$ & $44.7(4.3)$ & $\begin{array}{c}92.0 \\
(10.0) \\
\end{array}$ & $11.2(1.6)$ & $25.2(3.8)$ & $19.1(3.5)$ \\
\hline & $10 \mathrm{~mm}$ & 7.4 (1.9) & $15.1(4.5)$ & $13.2(4.2)$ & $12.4(2.9)$ & $23.5(6.9)$ & $46.1(3.5)$ & $94.5(7.8)$ & $12.4(1.7)$ & $27.8(3.9)$ & $21.6(3.5)$ \\
\hline & $12.5 \mathrm{~mm}$ & $8.6(2.1)$ & $17.7(4.7)$ & $15.7(4.5)$ & $14.3(3.0)$ & $27.7(7.2)$ & $47.2(2.6)$ & $96.8(5.8)$ & $13.6(1.7)$ & $30.4(4.0)$ & $24.2(3.6)$ \\
\hline & $15 \mathrm{~mm}$ & $9.8(2.2)$ & $20.5(5.0)$ & $18.3(4.7)$ & $16.3(3.1)$ & $32.1(7.4)$ & $48.0(1.8)$ & 98.2 (3.9) & $14.8(1.8)$ & $33.0(4.0)$ & $26.7(3.7)$ \\
\hline \multirow[t]{3}{*}{ Caudal } & $5 \mathrm{~mm}$ & $3.8(1.5)$ & $6.9(3.4)$ & $5.6(3.0)$ & $6.2(2.5)$ & $9.6(5.5)$ & $\begin{array}{c}36.2 \\
(10.0)\end{array}$ & $\begin{array}{c}74.2 \\
(24.3) \\
\end{array}$ & $7.9(1.4)$ & $17.9(3.5)$ & $\begin{array}{c}12.2 \\
(3 . .1) \\
\end{array}$ \\
\hline & $10 \mathrm{~mm}$ & $3.9(1.6)$ & $7.2(3.7)$ & $5.9(3.3)$ & $6.4(2.6)$ & $10.1(5.9)$ & $\begin{array}{c}36.4 \\
(10.6)\end{array}$ & $\begin{array}{c}74.2 \\
(25.6) \\
\end{array}$ & $8.0(1.4)$ & $18.1(3.4)$ & $12.5(3.0)$ \\
\hline & $15 \mathrm{~mm}$ & $4.1(1.7)$ & $7.5(4.0)$ & $6.2(3.6)$ & $6.6(2.8)$ & $10.6(6.3)$ & $\begin{array}{c}36.5 \\
(11.2)\end{array}$ & $\begin{array}{c}72.6 \\
(30.3)\end{array}$ & $8.1(1.4)$ & $18.3(3.3)$ & $12.7(3.0)$ \\
\hline
\end{tabular}

The prescribed dose was $50 \mathrm{~Gy}$ with 25 fractions in all plans.

Differences between DIBH and FB ( $\Delta \mathrm{FB}$ (Deep set-up - Original plan) - $\Delta \mathrm{DIBH}$ (Deep set-up - Original plan)) of mean heart and LV doses were $0.73 \mathrm{~Gy}(95 \% \mathrm{Cl}: 0.42-1.04 \mathrm{~Gy}, \mathrm{p}<0.001)$ and $1.27 \mathrm{~Gy}(95 \% \mathrm{Cl}$ : $0.65-1.88 \mathrm{~Gy}, \mathrm{p}<0.001)$ at $5 \mathrm{~mm}$ and $1.49 \mathrm{~Gy}(95 \% \mathrm{Cl}: 0.85-2.12 \mathrm{~Gy}, \mathrm{p}<0.001)$ and $2.31 \mathrm{~Gy}(95 \% \mathrm{Cl}$ : $1.06-3.57 \mathrm{~Gy}, \mathrm{p}=0.001$ ) at $10 \mathrm{~mm}$ deeper set-up.(Figures 2(a) and 2(b)). These results suggested that $\mathrm{DIBH}$ showed a relatively favorable dose distribution than FB in the case of deeper set-up uncertainty for the heart and the LV. Mean LAD dose with a deep set-up of $10 \mathrm{~mm}$ in DIBH was similar with the original plan of FB.(Figure 2(c)) Mean ipsilateral lung dose showed a qualitative increase of about 2 Gy per $5 \mathrm{~mm}$ 
deeper set-up regardless breath technique. It was $2.15 \pm 0.17$ Gy vs. $2.29 \pm 0.25$ Gy at $5 \mathrm{~mm}$ deep set-up and $4.40 \pm 0.35$ Gy vs. $4.63 \pm 0.52$ Gy at $10 \mathrm{~mm}$ deep set-up. (Figure 2(d)) Mean heart and LV doses of DIBH increased $49.4 \pm 14.5 \%$ and $56.4 \pm 24.2 \%$ at $5 \mathrm{~mm}$ deeper set-up and $119.6 \pm 38.9 \%$ and $143.6 \pm$ $68.5 \%$ at $10 \mathrm{~mm}$ deeper set-up, respectively.(Figure 3 )

In multiple comparison of DIBH, mean doses were significantly different in all $7.5 \mathrm{~mm}$ deep set-ups for the heart (mean difference: $1.56 \mathrm{~Gy}, \mathrm{p}=0.025$ ), the LV (mean difference: $2.87 \mathrm{~Gy}, \mathrm{p}=0.049$ ), and the LAD (mean difference: $13.58 \mathrm{~Gy}, \mathrm{p}=0.025$ ) in DIBH. The mean dose difference was more sensitive in FB with a $5 \mathrm{~mm}$ deep set-up for the heart (mean difference: $1.69 \mathrm{~Gy}, \mathrm{p}=0.012$ ), the LV (mean difference: $3.01 \mathrm{~Gy}$, $p=0.004$ ), and the LAD (mean difference: $7.02 \mathrm{~Gy}, \mathrm{p}=0.001$ ). For the mean ipsilateral lung dose, the difference was developed at $2.5 \mathrm{~mm}$ deep set-up in DIBH (mean difference: $1.05 \mathrm{~Gy}, \mathrm{p}=0.037$ ) and at 5 mm deep set-up in FB (mean difference: $2.27 \mathrm{~Gy}, \mathrm{p}<0.001$ ).(Table 3) If the practical action level to determine re-setup was given as $5 \mathrm{~mm}$ deep in DIBH, the maximum increases of V20 Gy for the heart, V20 Gy for the LV, V30 Gy for the LAD, and V30 Gy for ipsilateral lung were expected till $1.8 \pm 1.1 \%, 3.6 \pm 2.5 \%$, $21.6 \pm 20.3 \%$, and $4.5 \pm 0.4 \%$, respectively. 
Table 3. Mean dose differences of worsen errors against the original plan in deep set-up error. (Multiple comparisons with LSD method)

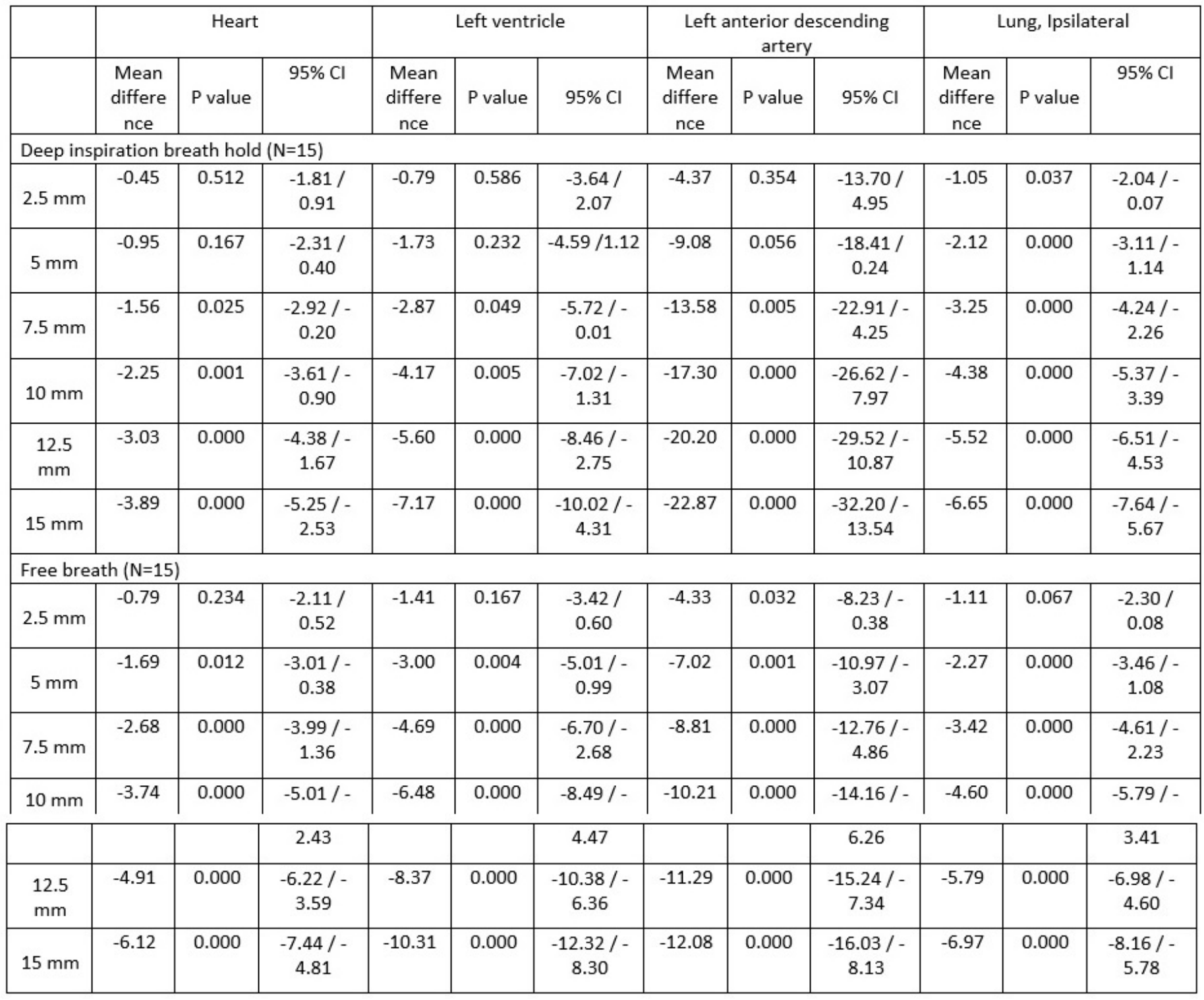

\section{Discussion}

Relatively modest set-up errors can meaningfully increase doses to the lung and heart. Under a deep setup error within $5 \mathrm{~mm}$, mean heart and ipsilateral lung doses increased up to $49.4 \%$ and $26.1 \%$ of original plan dose in DIBH, respectively. Compared to FB, DIBH can reduce the relative cardiac dose for the same extent of set-up errors in left breast cancer. It is necessary to keep in mind that radiation with a higher dose than the planned dose in actual radiation treatment could be irradiated. Thus, it is important to establish an action level for a set-up error suitable for treatment circumference of each institution.

\section{Conclusions}


Relatively modest set-up errors can meaningfully increase doses to the lung and heart. Under a deep setup error within $5 \mathrm{~mm}$, mean heart and ipsilateral lung doses increased up to $49.4 \%$ and $26.1 \%$ of original plan dose in DIBH, respectively. Compared to FB, DIBH can reduce the relative cardiac dose for the same extent of set-up errors in left breast cancer. It is necessary to keep in mind that radiation with a higher dose than the planned dose in actual radiation treatment could be irradiated. Thus, it is important to establish an action level for a set-up error suitable for treatment circumference of each institution.

\section{Abbreviations}

DIBH (Deep Inspiration Breath Holding)

FB (Free Breathing)

LV (Left ventricle)

LAD (left anterior descending coronary artery)

CTV (Clinical Target Volume)

CT (Computed Tomography)

OAR (Organs At Risk)

LSD (least significant difference)

OSS (optical surface scanning system)

\section{Declarations}

Ethics approval and consent to participate: Not applicable

Consent for publication: Not applicable

Availability of data and materials: The data that support the findings of this study are available in Ansan Hospital, Korea University.

Competing interests: The authors declare no conflict of interest.

Funding: This work was supported by Korea University [grant numbers K2010971].

Authors' contributions: WSY designed the overall study with contributions from SP. SP and CHR collected and analyzed data. All authors wrote and finally approved this manuscripts.

Acknowledgements: Not applicable 


\section{References}

1. Stewart FA, Seemann I, Hoving S, Russell NS. Understanding radiation-induced cardiovascular damage and strategies for intervention. Clin Oncol (R Coll Radiol). 2013;25(10):617-24.

2. Harris EE, Correa C, Hwang WT, Liao J, Litt HI, Ferrari VA, et al. Late cardiac mortality and morbidity in early-stage breast cancer patients after breast-conservation treatment. J Clin Oncol. 2006;24(25):4100-6.

3. Weberpals J, Jansen L, Muller OJ, Brenner H. Long-term heart-specific mortality among 347476 breast cancer patients treated with radiotherapy or chemotherapy: a registry-based cohort study. Eur Heart J. 2018;39(43):3896-903.

4. Taylor C, Correa C, Duane FK, Aznar MC, Anderson SJ, Bergh J, et al. Estimating the Risks of Breast Cancer Radiotherapy: Evidence From Modern Radiation Doses to the Lungs and Heart and From Previous Randomized Trials. J Clin Oncol. 2017;35(15):1641-9.

5. Darby SC, Ewertz M, McGale P, Bennet AM, Blom-Goldman U, Bronnum D, et al. Risk of ischemic heart disease in women after radiotherapy for breast cancer. N Engl J Med. 2013;368(11):987-98.

6. Smith BD, Bellon JR, Blitzblau R, Freedman G, Haffty B, Hahn C, et al. Radiation therapy for the whole breast: Executive summary of an American Society for Radiation Oncology (ASTRO) evidence-based guideline. Pract Radiat Oncol. 2018;8(3):145-52.

7. Yeung R, Conroy L, Long K, Walrath D, Li H, Smith W, et al. Cardiac dose reduction with deep inspiration breath hold for left-sided breast cancer radiotherapy patients with and without regional nodal irradiation. Radiat Oncol. 2015;10:200.

8. Yamauchi R, Mizuno N, Itazawa T, Saitoh H, Kawamori J. Dosimetric evaluation of deep inspiration breath hold for left-sided breast cancer: analysis of patient-specific parameters related to heart dose reduction. J Radiat Res. 2020;61(3):447-56.

9. Yoon WS, Das SK, Marks LB. The Impact of Set-Up Uncertainty on Dose-Response Estimates. Int J Radiat Oncol Biol Phys. 2019;105(3):477-8.

10. Offersen BV, Boersma LJ, Kirkove C, Hol S, Aznar MC, Biete Sola A, et al. ESTRO consensus guideline on target volume delineation for elective radiation therapy of early stage breast cancer. Radiother Oncol. 2015;114(1):3-10.

11. Duane F, Aznar MC, Bartlett F, Cutter DJ, Darby SC, Jagsi R, et al. A cardiac contouring atlas for radiotherapy. Radiother Oncol. 2017;122(3):416-22.

12. Seo YS, Kim MS, Kang JK, Jang WI, Kim HJ, Cho CK, et al. The Clinical Utilization of Radiation Therapy in Korea between 2011 and 2015. Cancer Res Treat. 2018;50(2):345-55.

13. Razvi Y, McKenzie E, Wronski M, Zhang L, Vesprini D, Bosnic S, et al. Factors Affecting Mean Heart Dose in Patients Receiving Breast Radiotherapy from 2011 to 2018 in a Single Institution. J Med Imaging Radiat Sci. 2020.

14. Poulsen PR, Thomsen MS, Hansen R, Worm E, Spejlborg H, Offersen B. Fully automated detection of heart irradiation in cine MV images acquired during breast cancer radiotherapy. Radiother Oncol. 
2019.

15. Kugele M, Mannerberg A, Norring Bekke S, Alkner S, Berg L, Mahmood F, et al. Surface guided radiotherapy (SGRT) improves breast cancer patient setup accuracy. J Appl Clin Med Phys. 2019;20(9):61-8.

16. Yang DS, Yoon WS, Chung SY, Lee JA, Lee S, Park YJ, et al. Set-up uncertainty during breast radiotherapy. Image-guided radiotherapy for patients with initial extensive variation. Strahlenther Onkol. 2013;189(4):315-20.

17. Tang X, Cullip T, Dooley J, Zagar T, Jones E, Chang S, et al. Dosimetric effect due to the motion during deep inspiration breath hold for left-sided breast cancer radiotherapy. J Appl Clin Med Phys. 2015;16(4):91-9.

18. Lutz CM, Poulsen PR, Fledelius W, Offersen BV, Thomsen MS. Setup error and motion during deep inspiration breath-hold breast radiotherapy measured with continuous portal imaging. Acta Oncol. 2016;55(2):193-200.

19. Bahig H, de Guise J, Vu T, Blais D, Chartrand-Lefebvre C, Nguyen NT, et al. In a Heartbeat: An Assessment of Dynamic Dose Variation to Cardiac Structures Using Dual Source Computed Tomography. Int J Radiat Oncol Biol Phys. 2018;102(4):950-9.

20. Hanania AN, Mainwaring W, Ghebre YT, Hanania NA, Ludwig M. Radiation-Induced Lung Injury: Assessment and Management. Chest. 2019;156(1):150-62.

21. Aznar MC, Duane FK, Darby SC, Wang Z, Taylor CW. Exposure of the lungs in breast cancer radiotherapy: A systematic review of lung doses published 2010-2015. Radiother Oncol. 2018;126(1):148-54.

22. Wen G, Tan YT, Lan XW, He ZC, Huang JH, Shi JT, et al. New Clinical Features and Dosimetric Predictor Identification for Symptomatic Radiation Pneumonitis after Tangential Irradiation in Breast Cancer Patients. J Cancer. 2017;8(18):3795-802.

23. McKenzie E, Razvi Y, Wronski M, Zhang L, Bosnic S, Vesprini D, et al. Trends and Correlates of Mean Lung Dose in Patients Receiving Breast Radiotherapy in a Single Institution from 2014 to 2018. Clin Oncol (R Coll Radiol). 2020.

24. Piroth MD, Baumann R, Budach W, Dunst J, Feyer P, Fietkau R, et al. Heart toxicity from breast cancer radiotherapy : Current findings, assessment, and prevention. Strahlenther Onkol. 2019;195(1):1-12.

\section{Figures}




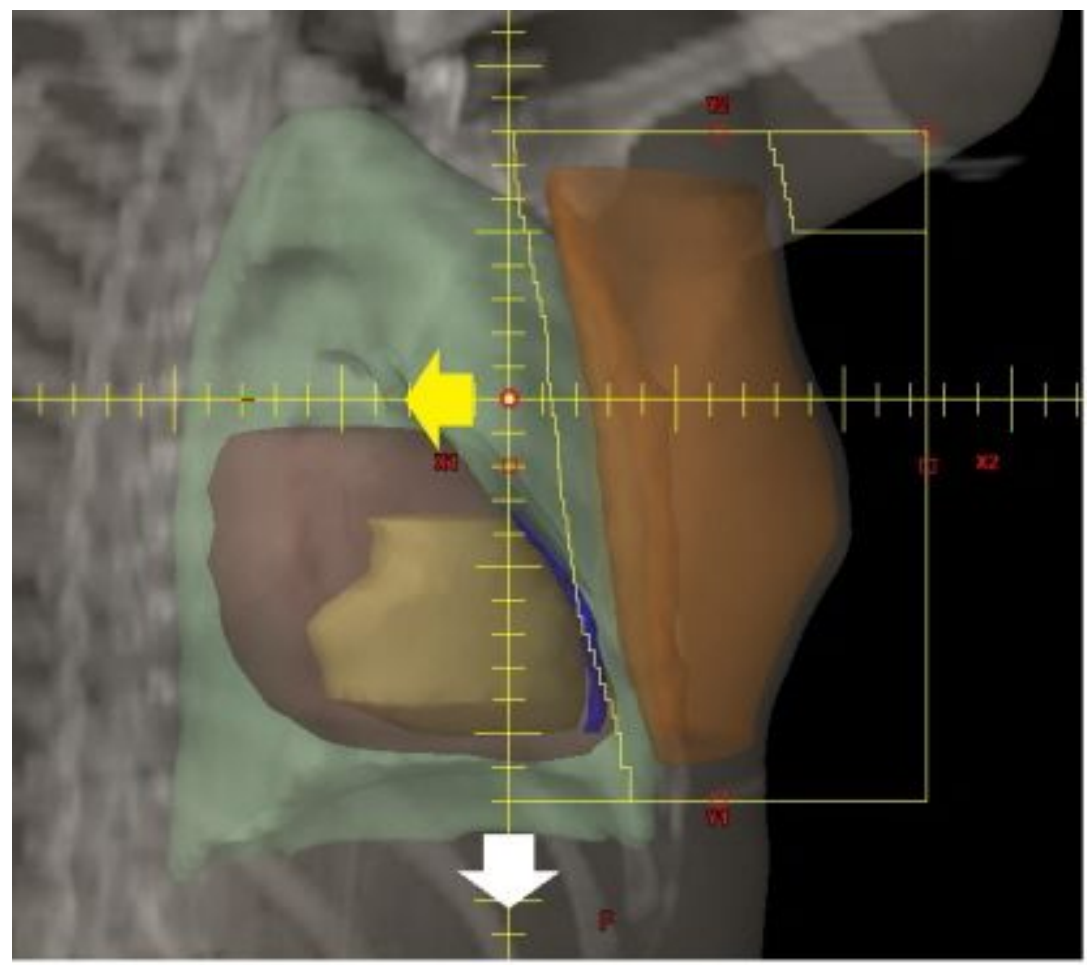

\section{Figure 1}

Beam's eye view of medial tangential field. After the organ at risks and target volume were drawn (Heart; brown, Left ventricle; yellow, left anterior descending coronary artery; blue, Lung; green, breast target volume; Orange) and original tangential fields were aligned, translation movement of deep (yellow arrow) and caudal (white arrow) directions was simulated in every $2.5 \mathrm{~mm}$ and $5 \mathrm{~mm}$ interval till $15 \mathrm{~mm}$ set-up error, respectively. 

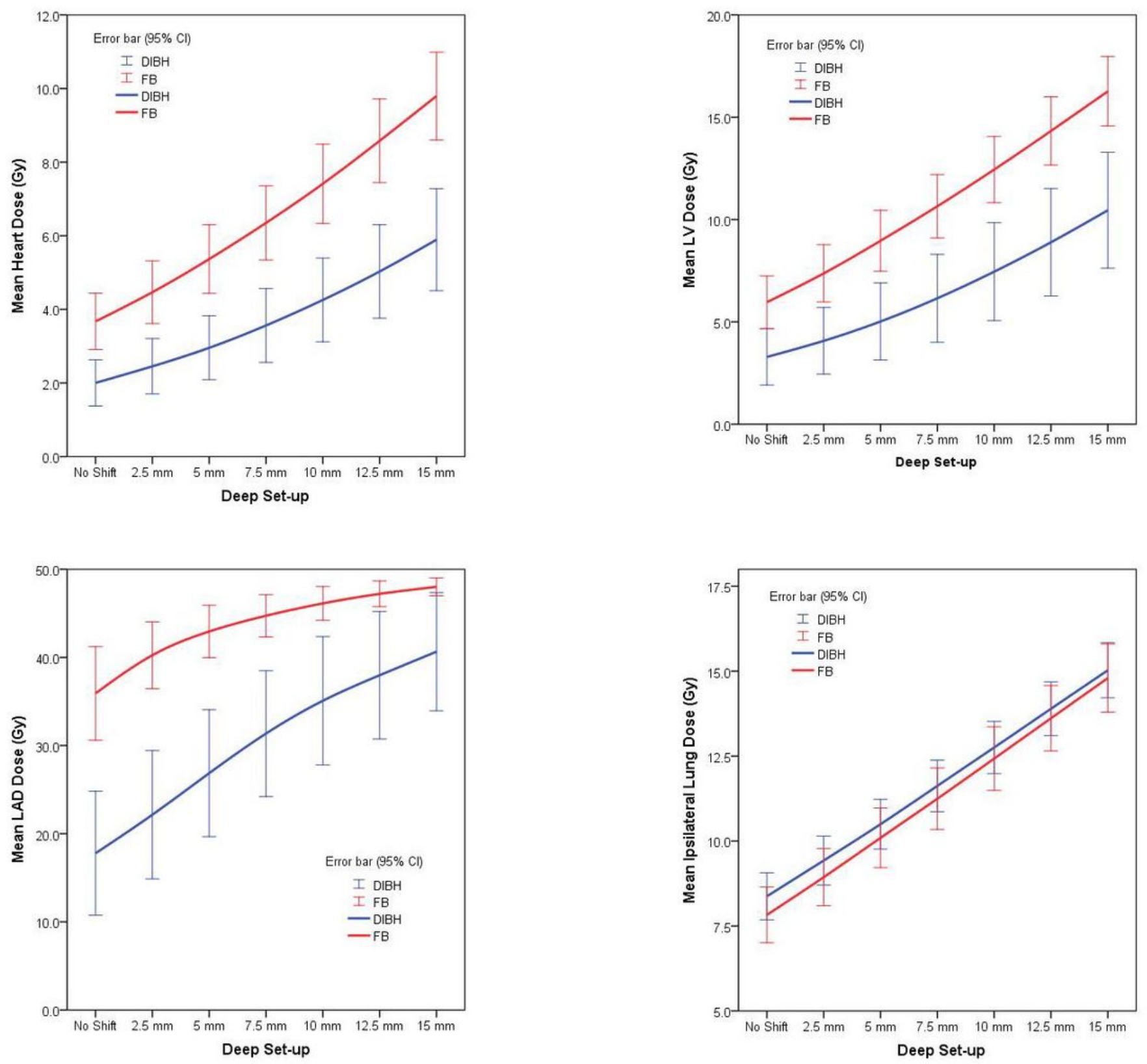

Figure 2

The increase of mean dose distribution (Gy) from the original plan to worsen errors in deep set-up error. (A) Heart, (B) Left ventricle, (C) Left anterior descending coronary artery, and (D) Ipsilateral lung. 


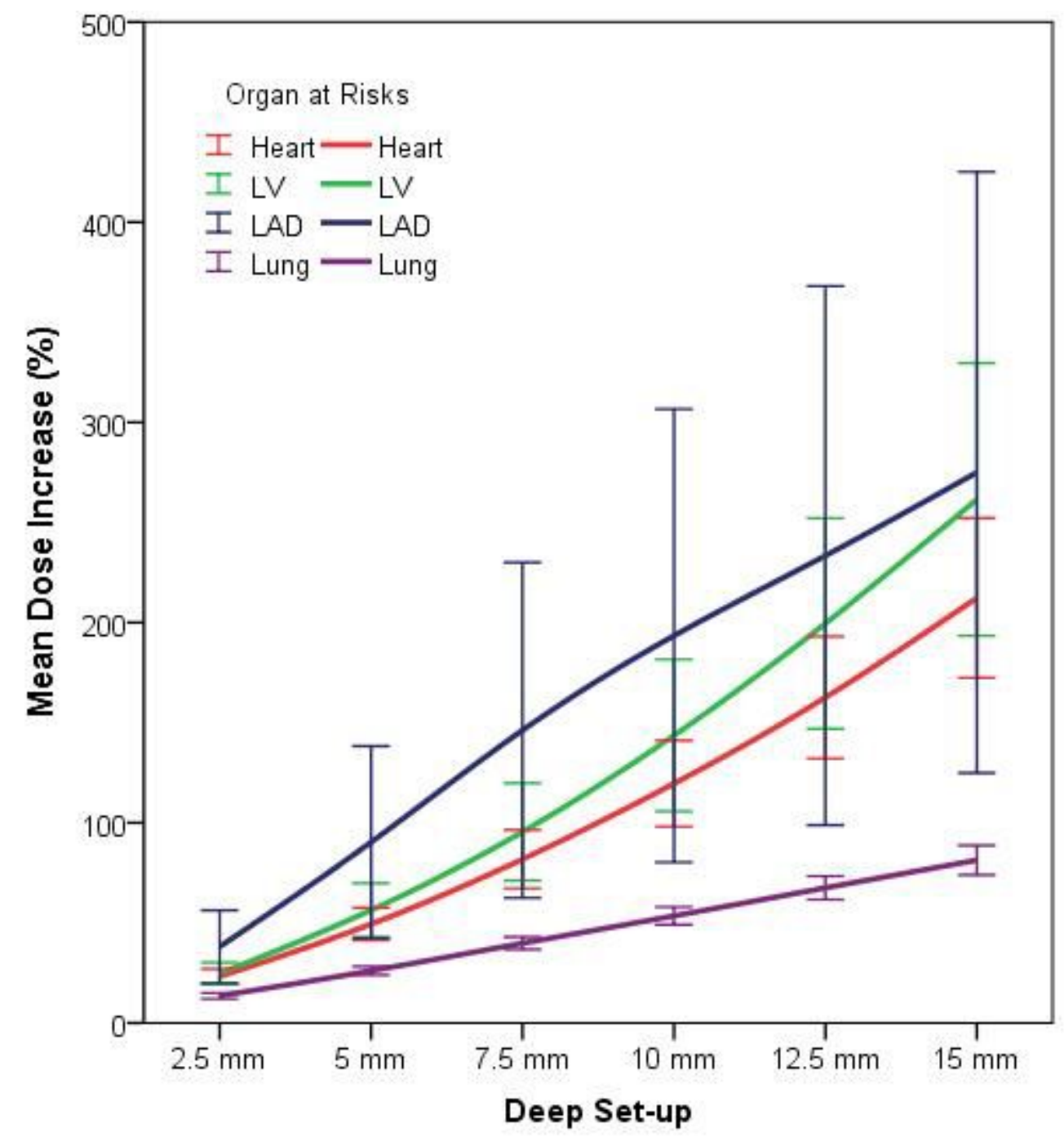

Figure 3

The changes of mean dose distribution (\%) of worsen errors against the original plan in deep set-up error of deep inspiration breath hold. 